\title{
Sistem Informasi Persediaan Barang Berbasis Web Pada PT. Wirausaha Muda Mandiri Jakarta
}

\author{
Mulyadi $^{1}$, Mochamad Nandi Susila ${ }^{2}$ \\ email: mulyadi.myd@bsi.ac.id, mochamad.mnl@bsi.ac.id \\ Universitas Bina Sarana Informatika
}

\begin{abstract}
Abstrak
Persediaan barang merupakan salah satu kegiatan penting dalam setiap perusahaan, terutama yang bergerak dibidang perdagangan. Dalam kesehariannya diperlukan pencatatan data-data transaksi dalam persediaan barang serta untuk membantu dalam mengelola persediaan barang maka diperlukan dukungaan sistem informasi yang baik. PT. Wirausaha Muda Mandiri adalah perusahaan yang bergerak dibidang perdangangan umum dan jasa EO (event organizer). Sistem persediaan barang sampai saat ini masih sangat sederhana dalam pencatatan persediaan barang seperti data barang masuk dan keluar, ketersediaan barang digudang dan juga dalam penyajian laporan, sehingga sering timbul masalah seperti terjadinya selisih dalam stok barang digudang, lamanya pencarian data karena ketika membutuhkan ketersediaan barang harus membuka dokumen secara satu persatu, untuk mengatasi masalah tersebut, maka diperlukan suatu sistem modern yang sesuai untuk mendukung kemajuan dan perkembangan perusahaan. Tujuan dari penelitian ini yaitu merancang suatu sistem informasi untuk memaksimalkan sistem yang sudah ada dengan menggunakan metode pengembangan perangkat lunak waterfall dan dukungan bahasa pemrograman PHP, serta Mysql server. Dengan memanfaatkan sistem yang sudah terkompterisasi dalam sebuah pemrograman ini secara tepat, kinerja pengawai atau kontrol terhadap pemrosesan persediaan barang menjadi lebih baik dan mudah dalam melakukan proses persediaan barang
\end{abstract}

Kata kunci : Sistem Informasi, Persediaan Barang, Metode Waterfall

\section{Pendahuluan}

Saat ini perkembangan teknologi terjadi sangat cepat dan meliputi dalam berbagai bidang baik di instansi pemerintahan maupun swasta. Dengan perkembangan tersebut berbagai instansi pemerintah dan swasta dituntut untuk menggunakan teknologi sesuai zamannya. Perkembangan teknologi pada saat ini lebih mengarah kepada sistem teknologi yang terkomputerisasi. Dengan adanya perkembangan tersebut perusahaan membutuhkan sistem dalam proses pengolahan data salah satunya yaitu sistem persediaan barang agar dapat diproses lebih efektif dan efisien serta mempermudah dan meningkatkan kualitas kerja.

Permasalahan yang sering terjadi pada persediaan barang seperti dalam pencatatan pembelian barang dagang yang terkadang terlalu banyak dibeli tetapi belum tentu dapat terjual semua sehingga barang dagang yang akan dipasarkan menjadi tidak terorganisir dengan baik dan menumpuk di bagian persediaan barang dagang atau gudang.(1)

Sistem informasi Persediaan barang yang ada pada PT. Solusi Aksesindo Pratama masih dilakukan secara manual, mulai dari pencatatan barang masuk, permintaan barang dari bagian sales, proses barang keluar oleh bagian gudang sampai kepada pembuatan laporan, sehingga memungkinkan pada saat proses berlangsung terjadi kesalahan dalam pencarian data-data yang diperlukan. (2)

Sistem persediaan barang yang berjalan saat ini masih dilakukan dengan menggunakan Microsoft Office Excel untuk mengolah data persediaan barang. Masalah yang dihadapi saat ini adalah tidak adanya sistem yang dapat membantu admin gudang dalam mengelola persediaan barang. Karena proses permintaan barang yang dilakukan oleh teknisi saat ini masih dengan cara manual dimana prosesnya menggunakan form sederhana dan proses pengecvekan persediaany barang masih dilakukan satu persatu sehingga petugas memerlukan waktu yang lama.(3)

Banyaknya data-data barang yang masih terpisah dan sulitnya mendapatkan informasi, membuat perusahaan harus menyediakan sistem yang terkomputerisasi untuk menyatukannya. Dalam hal ini, perusahaan masih mengalami masalah dipenyimpanan data-data pencatatan barang yang kurang teratur. Ini terjadi ketika datadata barang yang sudah dilakukan pengecekan, ditempatkan ke tempat yang tersedia tanpa adanya perencanaan alokasi terlebih 
dahulu dan mengakibatkan data-data terpisah.(4)

Setiap atktivitas keluar dan masuk barang dicatat ke kartu stok, sehingga saldo persediaan barang dagang pada setiap bulannya harus di-input kembali mengikuti saldo persediaan barang dagang bulan sebelumnya. Dalam aktivitas persediaan barang seperti ini besar kemungkinan bagian persediaan mengalami keterlambatan dalam melaporkan persediaan barang dagang, sering terjadinya kesalahan dalam pencatatan mutasi barang karena terdapat ribuan jenis barang dagang.(5)

Pembuatan laporan barang keluar, admin gudang menghitung jumlah barang keluar yang sudah dicatat perharinya sistem pencatatan yang manual mempunyai kekurangan terutama pada pencatatan dan penghitugan persediaan barang. Sering kali proses pencatatan persediaan yang dilakukan mengakibatkan selisih dari data jumlah stok barang dengan jumlah barang fisik yang ada setiap bulannya, mengakibatkan kerugian yang harus ditanggung perusahaan.(6)

PT. Sakura Yasa Prima adalah salah satu perusahaan yang saat ini pengolahan data persediaannya masih dikelola secara manual sehingga sistem berjalannya masih memiliki banyak kekurangan dan kelemahan sehingga hal ini menyebabkan kinerja perusahaan menjadi terhambat dan menyebabkan terjadi banyak kesalahan.(7)

$\begin{array}{lrcr} & \text { Permintaan } & \text { Barang dari } & \text { bagian } \\ \text { sales } & \text { kegudang } & \text { masih } & \text { dilakukan } \\ \text { dengan } & \text { cara } & \text { manualyaitu } & \text { dengan } \\ \text { membuat } & \text { surat permintaan } & \text { barang }\end{array}$

keluar.(8)

Jika jumlah inventory sedikit dan permintaan tidak dapat dipenuhi karena kekurangan persediaan maka dapat menghambat proses kerja.(9)

Proses pencarian data pun menjaditerkendala dan tidak efisien karena dokumen dicari secara manual.

Pada PT. Wirausaha Muda Mandiri belum menerapkan sistem informasi persediaan barang karena dalam prosesnya perusahaan ini masih sangat sederhana dalam pencatatan persediaan barang seperti data barang masuk dan keluar, ketersediaan barang di gudang dan juga dalam penyajian laporan. Masalahnya adalah sering terjadi selisih dalam stok barang digudang dan ketika membutuhkan ketersediaan barang harus membuka dokumen secara satu persatu. Hal ini dirasa tidak efektif dan efisien. Karena itu dibutuhkan sistem informasi yang dapat menunjang kebutuhan informasi perusahaan lebih efektif dan efisien dalam pengelolaan persediaan.

\section{Metode Penelitian}

Dalam pengembangan perangkat lunak, disiplin ilmu yang sering digunakan sebagai dasar pemodelan pengembangan perangkat lunak menggunakan model waterfall.

Model SDLC air terjun (waterfall) sering juga disebut model sekuensial linier (sequential linear) atau alur hidup klasik (classic life cycle). Model air terjun menyediakan pendekatan alur hidup perangkat lunak secara sekuensial atau terurut dimulai dari analisis, desain, pengodean, pengujian, dan tahap pendukung (support)" (10)

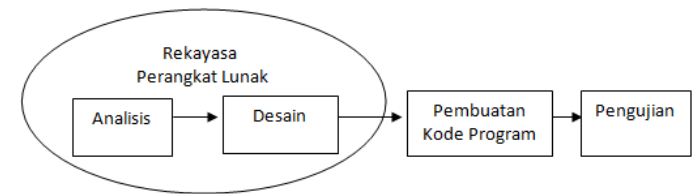

Gambar 1. Metode Waterfall

Pada penulisan Tugas Akhir ini penulis membutuhkan analisa kebutuhan, yang dibutuhkan untuk menunjang sistem persediaan yang sudah terkomputerisasi. Analisa kebutuhan tersebut dimulai dari bahasa pemrograman PHP (Hypertext Preprocessor) dan software Sublime Text 3.2. Selain itu, penulis menggunakan database untuk menyimpan data dengan menggunakan database MySQL dengan software Xampp.

Setelah penulis menganalisis kebutuhan software yang digunakan, selanjutnya penulis mendesain dari peralatan pendukung yang akan digunakan, mulai dari Unified Modelling Language (UML), beberapa diantaranya yang terdiri dari Use Case Diagram, Activity Diagram, Sequence Diagram dan Deployment Diagram. Selain itu, tools system lainnya berupa Entity Relationship Diagram (ERD), Logical Record Struktur (LRS), dan Spesifikasi file. Penulis juga membuat rancangan tampilan user interface, mulai dari data user, data barang masuk, data barang keluar, data supplier, laporan persediaan barang, sampai dengan jurnal umum persediaan.

Dari desain yang telah dibuat, baik berupa data user, data barang masuk, data 
barang keluar, data supplier, laporan persediaan barang, dan jurnal umum persediaan dibuat menggunakan script atau bahasa pemrograman berupa PHP script dan database MySQL.

Pada tahap ini, setelah melakukan analisa kebutuhan, desain sistem dan pembuatan kode program. Penulis melakukan pengujian untuk mengetahui kebenaran atau kesalahan dari aplikasi yang telah dibangun dengan menggunakan black box testing sebagai tahap pengujian.

Untuk menunjang aplikasi berjalan maka diperlukan peralatan, baik itu software ataupun hardware yang digunakan sehingga sistem dapat berjalan dengan baik, dan perlu dilakukan maintenance guna menjaga performance sistem untuk mencegah kerusakan data serta perlu dilakukan pembackup-an data untuk menjaga keamanan

\section{Hasil dan Pembahasan}

3.1 Analisa Kebutuhan

A. Analisa kebutuhan Warehouse Keeper
A.1. Warehouse Keeper dapat melakukan login dengan akun yang telah dibuat

A.2. Warehouse Keeper dapat mengakses menu transaksi.
A.3. Warehouse Keeper dapat mengelola data barang masuk.

A.4. Warehouse Keeper dapat mengelola data barang keluar.
A.5. Warehouse Keeper dapat mengelola data persediaan barang.
A.6. Warehouse Keeper dapat melakukan logout dari sistem.

B. Analisa kebutuhan Halaman Administrator

B.1. Administrator dapat melakukan login dengan akun yang telah dibuat.

B.2. Administrator dapat mengakses menu master.

B.3. Administrator dapat mengelola data perusahaan.

B.4. Administrator dapat mengelola data supplier.

B.5. Administrator dapat mengelola data persediaan barang.

B.6. Administrator dapat mengelola data user.

B.7. Administrator dapat mengakses menu transaksi
B.8. Administrator dapat mengelola data barang masuk.

B.9. Administrator dapat mengelola data barang keluar.

B.10. Administrator dapat mengakses menu laporan.

B.11. Administrator dapat melihat data jurnal umum persediaan barang.

B.12. Administrator dapat mencetak data laporan barang masuk, barang keluar dan profit.

B.13. Administrator dapat melakukan logout dari sistem.

C. Analisa kebutuhan Halaman Purchasing

C.1. Purchasing dapat melakukan login dengan akun yang telah dibuat.

C.2. Purchasing dapat mengelola data supplier.

C.3. Purchasing dapat melakukan logout dari sistem.

D. Analisa kebutuhan Halaman Manager

D.1. Manager dapat melakukan login dengan akun yang telah dibuat.

D.2. Manager dapat mengakses menu laporan.

D.3. Manager dapat mencetak data laporan barang masuk, barang keluar dan profit.

D.4. Manager dapat melihat data jurnal umum persediaan barang.

D.5. Manager dapat melakukan logout dari sistem.

\subsection{Desain Sistem}

A. Use Case Diagram

Berikut adalah hasil dari pembuatan use case diagram

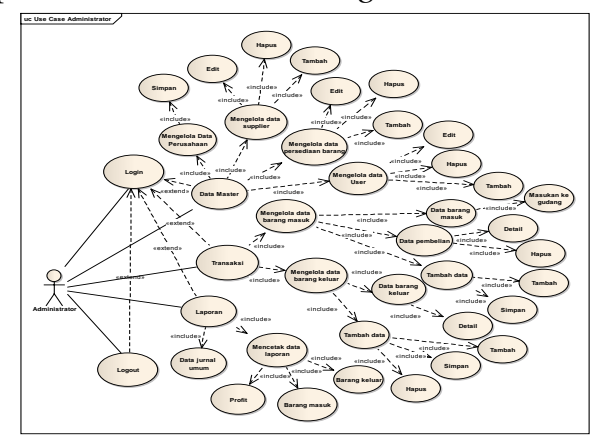

Gambar 2. Use Case Diagram 
B. Activity Diagram

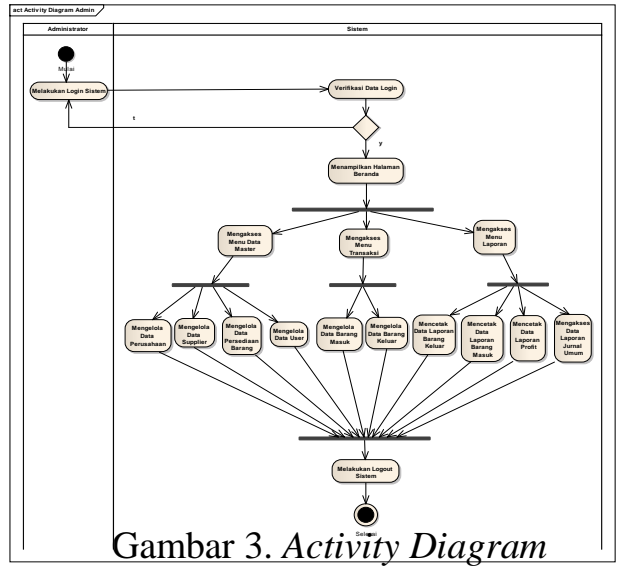

C. Entity Relationship Diagram

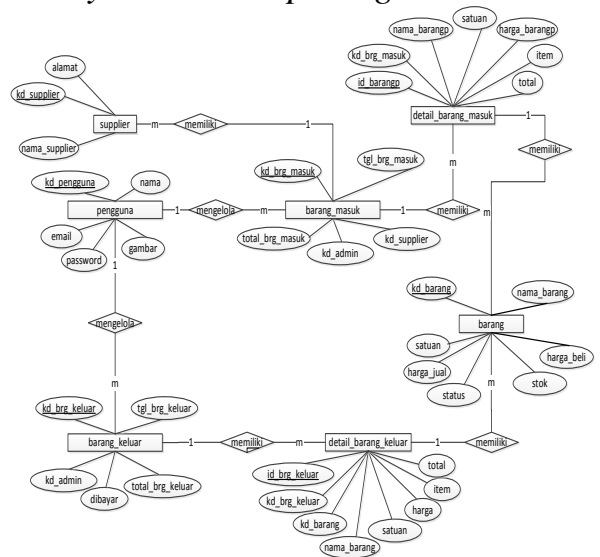

Gambar 4. Entity Relationship Diagram

E. Pengujian Sistem Informasi

Tabel 1. Hasil Pengujian Black Box Testing

\begin{tabular}{|c|c|c|c|c|c|}
\hline No & Skenario pengujian & Test Case & $\begin{array}{c}\text { Hasil yang } \\
\text { diharapkan }\end{array}$ & $\begin{array}{c}\text { Hasil } \\
\text { pengujian }\end{array}$ & Kesimpulan \\
\hline 1 & $\begin{array}{l}\text { Username dan password } \\
\text { tidak diisi kemudian klik } \\
\text { tombol login }\end{array}$ & $\begin{array}{l}\text { Username: } \\
\text { (kosong) } \\
\text { Password: } \\
\text { (kosong) }\end{array}$ & $\begin{array}{l}\text { Sistem akan menolak } \\
\text { akses dan } \\
\text { menampilkan "Login } \\
\text { Gagal,Password/Ema } \\
\text { il Salah!" }\end{array}$ & $\begin{array}{l}\text { Sesuai } \\
\text { harapan }\end{array}$ & Valid \\
\hline 2 & $\begin{array}{l}\text { Username diidi dan } \\
\text { password tidak diisi } \\
\text { kemudian klik tombol } \\
\text { login }\end{array}$ & $\begin{array}{l}\text { Username: } \\
\text { wisnu@ gmail.com } \\
\text { Password: } \\
\text { (kosong) }\end{array}$ & $\begin{array}{l}\text { Sistem akan menolak } \\
\text { akses dan } \\
\text { menampilkan "Login } \\
\text { Gagal,Password / } \\
\text { Email Salah!" }\end{array}$ & $\begin{array}{l}\text { Sesuai } \\
\text { harapan }\end{array}$ & Valid \\
\hline 3 & $\begin{array}{l}\text { Username tidak diisi dan } \\
\text { password diisi kemudian } \\
\text { klik tombol login }\end{array}$ & $\begin{array}{l}\text { Username : } \\
\text { (kosong) } \\
\text { Password : wisnu }\end{array}$ & $\begin{array}{l}\text { Sistem akan menolak } \\
\text { akses dan } \\
\text { menampilkan "Login } \\
\text { Gagal,Password / } \\
\text { Email Salah!" }\end{array}$ & $\begin{array}{l}\text { Sesuai } \\
\text { harapan }\end{array}$ & Valid \\
\hline 4 & $\begin{array}{c}\text { Mengetikkan salah satu } \\
\text { kondisi salah pada } \\
\text { username atau password } \\
\text { kemudian klik tombol } \\
\text { login } \\
\end{array}$ & $\begin{array}{l}\text { Username : (salah) } \\
\text { Password : (benar) }\end{array}$ & $\begin{array}{l}\text { Sistem akan menolak } \\
\text { akses dan } \\
\text { menampilkan "Login } \\
\text { Gagal, Password / } \\
\text { Email Salah!" } \\
\end{array}$ & $\begin{array}{l}\text { Sesuai } \\
\text { harapan }\end{array}$ & Valid \\
\hline 5 & $\begin{array}{l}\text { Mengetikkan username } \\
\text { atau password yang benar }\end{array}$ & $\begin{array}{l}\text { Username : (benar) } \\
\text { Password: (benar) }\end{array}$ & $\begin{array}{c}\text { Sistem akan } \\
\text { menerima akses login }\end{array}$ & $\begin{array}{c}\text { Sesuai } \\
\text { harapan }\end{array}$ & Valid \\
\hline
\end{tabular}

D. User Interface Sistem Informasi

a. User Interface Dashboard

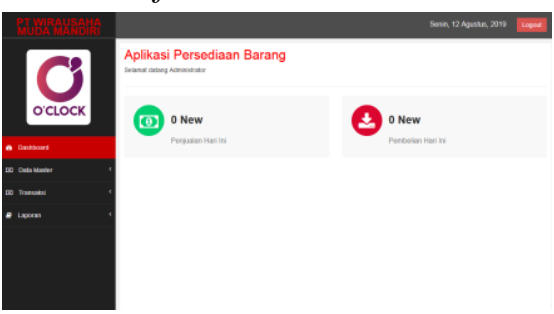

Gambar 5. User Interface Dashboard

b. User Interface Laporan

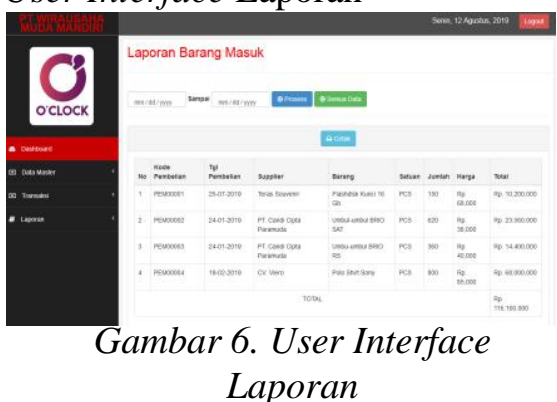




\begin{tabular}{|c|c|}
\hline & $\begin{array}{c}\text { kemudian klik tombol } \\
\text { login }\end{array}$ \\
\end{tabular}

\section{Kesimpulan}

Sistem yang terjadi pada perusahaan ini masih sangat sederhana yaitu dalam proses pencatatan persedian barang baik barang masuk maupun barang keluar. Sehingga sistem informasi persediaan barang yang dirancang oleh peneliti dapat menunjang prosedur sistem yang sudah berjalan sebelumnya. Dengan sistem berbasis data, maka backup data harus selalu dilakukan agar implementasi sistem informasi dapat terjaga dengan baik.

\section{Daftar Pustaka}

[1] Sari DK, Effendi R. Peran sistem informasi akuntansi dalam pengendalian persediaan barang dagang pada CV. Graha Gallery Palembang. 2014;

[2] Sari AO, Nuari E. RANCANG BANGUN SISTEM INFORMASI PERSEDIAAN BARANG BERBASIS WEB DENGAN METODE FAST (FRAMEWORK FOR THE APPLICATIONS ). 2017;13(2):261-6.

[3] Hakim Z, Sakuroh L, Awaludin S, Stmik D, Sarana B, Stmik M, et al. Sistem Informasi Persediaan Barang Berbasis Web Pada CV Telaga Berkat. 2019;9(1). $\begin{array}{llr}\text { [4] Hardiansyah, } & \text { Farizy } & \text { S. } \\ \text { PERANCANGAN } & & \text { SISTEM }\end{array}$ INFORMASI PERSEDIAN BARANG DENGAN MENGGUNAKAN PYTHON. 2020;III(3):32-4.

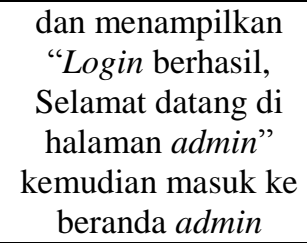

[5] Ramdhany T, Kurnia D. DI PT DIMARCO MITRA UTAMA. 2016;3:19-26.

[6] Perancangan ADAN, Jambi PTS, Meisak D. MENGGUNAKAN METODE FIFO PADA. 2017;11(2):862-75.

[7] Nawang M, Kurniawati L, Duta D, Akuntansi K, Informasi S, Akuntansi K. RANCANG BANGUN SISTEM INFORMASI PENGOLAHAN DATA PERSEDIAAN BARANG BERBASIS DEKSTOP DENGAN MODEL. 2017;13(2):233-8.

[8] Rakhman, A., \& Sabanise, A. Y. F. (2019). Sistem Informasi Stok Kebutuhan Darah Pada Palang Merah Indonesia Dengan Metode Weighted Moving Average. Syntax Literate; Jurnal Ilmiah Indonesia, 4(7), 24-32.

[9] Sarwindah. Sistem informasi manajemen pemesanan buku pada toko buku nuris. TEKNOSI. 2016;2(2).

[10] Sampeallo YG. Analisis pengendalian persediaan pada UD Bintang Furniture Sangasanga. J eksis. 2012;8(1).

[11] A.S R, Shalahuddin M. Rekayasa Perangkat Lunak Terstruktur dan Berorientasi Objek. Bandung: Informatika; 2013. 